\title{
Acoustic field modulation in regenerators
}

\author{
J. Y. Hu ${ }^{\text {a }}$, W. Wang ${ }^{\text {a, b }}$, E. C. Luo ${ }^{\text {a }}$, Y. Y. Chen ${ }^{\text {a }}$ \\ ${ }^{a}$ Key Laboratory of Cryogenics, Technical Institute of Physics and Chemistry, Chinese \\ Academy of Sciences, Beijing 100190, China \\ ${ }^{\mathrm{b}}$ University of the Chinese Academy of Sciences, Beijing, 100039, China
}

\begin{abstract}
The regenerator is a key component that transfers energy between heat and work. The conversion efficiency is significantly influenced by the acoustic field in the regenerator. Much effort has been spent to quantitatively determine this influence, but few comprehensive experimental verifications have been performed because of difficulties in modulating and measuring the acoustic field. In this paper, a method requiring two compressors is introduced and theoretically investigated that achieves acoustic field modulation in the regenerator. One compressor outputs the acoustic power for the regenerator; the other acts as a phase shifter. A RC load dissipates the acoustic power out of both the regenerator and the latter compressor. The acoustic field can be modulated by adjusting the current in the two compressors and opening the RC load. The acoustic field is measured with pressure sensors instead of flow-field imaging equipment, thereby greatly simplifying the experiment.

Key words: regenerator; acoustic field; modulation; pulse tube cryocooler
\end{abstract}




\begin{tabular}{|c|c|c|c|}
\hline \multicolumn{4}{|c|}{ Nomenclature } \\
\hline $1, \mathrm{C} 1$ & Compressor 1 & $2, \mathrm{C} 2$ & Compressor 2 \\
\hline 3 & $\begin{array}{l}\text { double-acting piston facing to } \\
\text { the orifice, the chamber } \\
\text { between the double-acting } \\
\text { piston and the orifice }\end{array}$ & $A$ & piston area $\left(\mathrm{m}^{2}\right)$ \\
\hline $\operatorname{Arg}$ & phase of a complex number & back & back space of compressor \\
\hline com & $\begin{array}{l}\text { Regenerative component's end } \\
\text { facing to the compression } \\
\text { chamber }\end{array}$ & $D$ & diameter $(\mathrm{m})$ \\
\hline elec & electric & $\exp$ & $\begin{array}{l}\text { Regenerative component's end } \\
\text { facing to the expansion chamber }\end{array}$ \\
\hline$i$ & $\sqrt{-1}$ & $I$ & current (A) \\
\hline $\operatorname{Im}$ & $\begin{array}{l}\text { imaginary part of a complex } \\
\text { number }\end{array}$ & $K$ & spring constant $(\mathrm{N} / \mathrm{m})$ \\
\hline mech & mechanical & $M$ & piston mass (kg) \\
\hline opt & optimal & ori & orifice \\
\hline$p$ & fluctuanting pressure $(\mathrm{Pa})$ & $P_{a}$ & average pressure $(\mathrm{Pa})$ \\
\hline res & reservoir & $\operatorname{Re}$ & real part of a complex number \\
\hline$T$ & transmission matrix & $U$ & volume flow rate $\left(\mathrm{m}^{3} / \mathrm{s}\right)$ \\
\hline$v$ & velocity $(\mathrm{m} / \mathrm{s})$ & $V$ & volume $\left(\mathrm{m}^{3}\right)$ \\
\hline$W$ & work (W) & $Z$ & acoustic impedance, impedance \\
\hline$\Delta V$ & voltage $(\mathrm{V})$ & $\gamma$ & specific heat ratio \\
\hline$\tau$ & transduction coefficient (N/A) & $\omega$ & angular frequency (rad/s) \\
\hline $1 \mid$ & $\begin{array}{l}\text { magnitude of a complex } \\
\text { number }\end{array}$ & & \\
\hline
\end{tabular}




\section{INTRODUCTION}

Qualitatively, the efficiency of a regenerator in a cryocooler or a thermoacoustic prime mover is generally maximized when the pressure and flow are in phase although the acoustic field does not determine the performance alone. Such a phase relationship minimizes the magnitude of mass flow for a given acoustic power through the regenerator [1]. Since Gifford and Longsworth invented the pulse tube cryocooler, its phase shifter has been changed many times, from basic to orifice to double-inlet type, and finally an inertance-tube type [2-6]. Each change was accompanied by an improvement in efficiency. The evolution in configuration actually provides a more ideal acoustic field in the regenerators. A similar evolution is also seen with the thermoacoustic prime mover. With the realization that standing-wave thermoacoustic engines were based on an intrinsically irreversible thermodynamic cycle, attention was quickly turned to traveling-wave thermoacoustic engines with reversible thermodynamic cycles that yielded higher efficiency [7, 8].

Quantitative studies using numerical methods have shown that the acoustic field influences the power capacity and efficiency $[9,10]$. However, few experiments have been performed. Indeed, the task experimentally for the experimenter is in creating a large number of different acoustic fields to test performance. For example, if an inertance tube is employed as the phase shifter, its dimensions have to be changed many times [11]. At the same time, the flow field imaging techniques such as hot-wire anemometry, particle image velocimetry, or laser Doppler velocimetry are also employed to measure the volume flow, which is an important parameter of an actual acoustic field to know; otherwise, the theoretical and experimental results cannot be compared [12]. The equipment required makes the experiment 
very complicated and troublesome. A simple method that produces different acoustic fields is much needed.

In [13], Wu used a linear compressor and a linear electric generator to test the performance of a thermoacoustic prime mover. The compressor produces the pressure wave. The electric generator, which was connected to the secondary water-cooler, absorbed the acoustic power. Changing the electric resistance, compliance, and piston mass of the generator changes the impedance of the generator as well as the acoustic field in the regenerator. The volume flow rate in front of the piston can be obtained by measuring the movement of the piston, which is much simpler to perform than the above-mentioned flow field imaging techniques. In principle, this method can also be applied in a regenerative cryocooler. However, changing the parameters of the generator is still troublesome. The number of acoustic fields realized with this method is still limited. In [14], Zhou used two loudspeakers and two resonance tubes to modulate the acoustic field in a regenerator. By changing the voltages on the two loudspeakers, the movement of coils can be adjusted. Thus, it is possible for the experimenter to realize different acoustic fields easily. In this method, the resonance tubes dissipated the power and altered the phase. If the volume flow at the two ends of the regenerator is required, flow field imaging equipment is still necessary because no models can precisely predict the volume flow from the movement of the coils, especially when the pressure is high. Furthermore, changing the length of the resonance tube is very inconvenient. There are also some other modulation methods [15-18]. However, the acoustic fields obtained with these methods are very limited and the experiment processes are inconvenient. 
$\mathrm{Wu}$ and Zhou's methods inspired the question: Can we use two linear compressors connected to the two ends of the regenerator to modulate the acoustic field? As is known, an acoustic wave flows in at one end of the regenerator and out the other. If the compressor at the other end also outputs an acoustic wave, the two waves compete because neither can be absorbed nor can the power be dissipated. This is also the reason that Wu used a generator and Zhou used a long resonator. Hence, this method seems infeasible. Although a compressor cannot absorb the acoustic power, some other dissipator such as a RC load can be employed. Therefore, it is very plausible that two compressors and a RC load can modulate an acoustic field. This paper details the concept.

\section{THEORETICAL ANALYSIS}

Figure 1 presents two configurations for field modulation. Each mainly comprises four parts: two linear compressors (only the pistons are shown), a regenerative component, and a $\mathrm{RC}$ load. The regenerative component can either be a prime mover or cryocooler. The RC load consists of an orifice and a reservoir. In Config. 1, the RC load is installed between the regenerative component and Compressor 2 (C2). In Config. 2, the compressor employs a double-acting piston. The RC-load is attached to the right of the piston. For simplicity, the volume of the compression and expansion chamber can be considered as part of the regenerative component, so it is not taken into consideration in the following analysis and calculations.

\subsection{Analysis on Config. 1}


A transmission matrix correlates the volume flow rates $\left(U_{\text {com }}\right.$ and $\left.U_{\text {exp }}\right)$ and pressures $\left(p_{\text {com }}\right.$ and $\left.p_{\text {exp }}\right)$ at the two ends of the regenerative component [19],

$$
\left[\begin{array}{l}
p_{\text {exp }} \\
U_{\text {exp }}
\end{array}\right]=\left[\begin{array}{ll}
T(1,1) & T(1,2) \\
T(2,1) & T(2,2)
\end{array}\right]\left[\begin{array}{l}
p_{\text {com }} \\
U_{\text {com }}
\end{array}\right]
$$

If the impedance at the right end is $Z_{\text {exp }}$, the impedance $Z_{c o m}$ at the left end can be expressed as

$$
Z_{\text {com }}=\frac{p_{\text {com }}}{U_{\text {com }}}=\frac{T(1,2)-T(2,2) Z_{\text {exp }}}{T(2,1) Z_{\text {exp }}-T(1,1)}
$$

with the volume flow rates correlated as

$$
\frac{U_{\text {exp }}}{U_{\text {com }}}=T(2,1) Z_{\text {com }}+T(2,2)=T(2,1) \frac{T(1,2)-T(2,2) Z_{\text {exp }}}{T(2,1) Z_{\text {exp }}-T(1,1)}+T(2,2) .
$$

For Compressor $1(\mathrm{C} 1)$, we have [10]

$$
\begin{aligned}
& \Delta V_{1}=Z_{\text {elec }, 1} I_{1}+\tau_{1} v_{1}, \\
& p_{\text {com }} A_{1}=\tau_{1} I_{1}-Z_{\text {mech }, 1} v_{1}, \\
& v_{1} A_{1}=U_{\text {com }},
\end{aligned}
$$

and similarly for Compressor 2 (C2),

$$
\begin{aligned}
& \Delta V_{2}=Z_{\text {elec }, 2} I_{2}+\tau_{2} v_{2}, \\
& p_{\text {exp }} A_{2}=\tau_{2} I_{2}-Z_{\text {mech }, 2} v_{2} .
\end{aligned}
$$

In the expansion chamber, we have

$$
v_{2} A_{2}=p_{\text {exp }} / Z_{\text {ori }}-U_{\text {exp }},
$$

where $\Delta V, Z, I, \tau, v$, and $A$ denote voltage, impedance, current, transduction coefficient, velocity, and piston area, respectively. Subscripts 1, 2, elec, mech, acou, and ori denote C1, C2, electrical, mechanical, acoustic, and orifice, respectively. From Eqs. (5) and (6), we obtain

$$
U_{c o m}=\frac{I_{1} \tau_{1} A_{1}}{Z_{c o m} A_{1}^{2}+Z_{m e c h, 1}}
$$


and from Eqs. (8) and (9), we obtain

$$
U_{\text {exp }}=\frac{\tau_{2} I_{2} A_{2}}{Z_{\text {exp }} A_{2}^{2}+Z_{\text {mech, }, 2} Z_{\text {exp }} / Z_{\text {ori }}-Z_{\text {mech }, 2}}
$$

Substituting Eqs. (10) and (11) into Eq. (3) yields

$$
\frac{\tau_{2} I_{2} A_{2}}{Z_{\text {exp }} A_{2}^{2}+Z_{\text {mech }, 2} \frac{Z_{\text {exp }}}{Z_{\text {ori }}}-Z_{\text {mech }, 2}}=\frac{I_{1} \tau_{1} A_{1}}{A_{1}^{2} \frac{T(1,2)-T(2,2) Z_{\text {exp }}}{T(2,1) Z_{\text {exp }}-T(1,1)}+Z_{\text {mech }, 1}}\left[T(2,1) \frac{T(1,2)-T(2,2) Z_{\text {exp }}}{T(2,1) Z_{\text {exp }}-T(1,1)}+T(2,2)\right] .
$$

Therefore, given $Z_{\text {exp }}$ and $p_{\text {exp }}$, the current in $\mathrm{C} 2 I_{2}$ is obtainable from Eq. (11). Then, the current in $\mathrm{C} 1 I_{1}$ is obtainable from Eq. (12), which implies that any acoustic field can be satisfied by the two currents.

For a RC load with a reservoir of volume $V_{\text {res }}$, the volume flow rate into the reservoir $U_{\text {ori }}$ can be obtained easily and accurately from measurement of the pressure in it $p_{\text {res }}[20]$,

$$
U_{o r i}=\frac{i \omega p_{r e s} V_{r e s}}{\gamma P_{a}}
$$

Thus, the acoustic impedance of the RC load can be calculated from pressure readings in the expansion chamber and reservoir,

$$
Z_{\text {ori }}=\frac{p_{\text {exp }}}{U_{\text {ori }}}=\frac{\gamma p_{\text {exp }} P_{a}}{i \omega p_{\text {res }} V_{\text {res }}}
$$

where $P_{a}, \omega$ and $\gamma$ denote the average pressure, angular frequency and specific heat ratio, respectively. Similarly, the volume flow rate of a moving piston can also be inferred from pressure measurement in the back space of a compressor experiencing spatially uniform pressure oscillations. Thus, the acoustic impedance in front of the piston of $\mathrm{C} 2 Z_{2}$ can be calculated from

$$
Z_{2}=\frac{p_{\text {exp }}}{U_{2}}=\frac{\gamma p_{\text {exp }} P_{a}}{i \omega p_{\text {back,2 }} V_{\text {back, }}}
$$

Subscript back denotes the back space of the compressor. The two impedances then yield the impedance $Z_{\text {exp }}$ 


$$
Z_{\text {exp }}=\frac{1}{1 / Z_{\text {ori }}-1 / Z_{2}}=\frac{\gamma p_{\text {exp }} P_{a}}{i \omega\left(p_{\text {res }} V_{\text {res }}-p_{\text {back }, 2} V_{\text {back }, 2}\right)},
$$

Hence, for experimental analysis, the practical acoustic field can be obtained from $p_{\text {res }}, p_{\text {exp }}$ and $p_{\text {back,2 }}$ without any flow field imaging equipment. In experiment for a regenerative component, all that is needed to be done is adjusting the currents in the two compressors and monitoring the pressures.

\subsection{Analysis on Config. 2}

For $\mathrm{C} 1$ and $\mathrm{C} 2$, the equations are the same as Eqs. (4)-(7), but Eq. (8) should be rewritten as

$$
p_{3} A_{3}-p_{\text {exp }} A_{2}=\tau_{2} I_{2}-Z_{m e c h, 2} v_{2}
$$

For simplicity, let $A_{2}=A_{3}$, then Eq. (17) yields

$$
U_{\text {exp }}=\frac{I_{2} \tau_{2} A_{2}}{Z_{3} A_{2}^{2}-Z_{\text {exp }} A_{2}^{2}+Z_{m e c h, 2}} .
$$

Substituting Eqs. (10) and (18) into Eq. (3) yields,

$\frac{I_{2} \tau_{2} A_{2}}{Z_{3} A_{2}^{2}-Z_{\text {exp }} A_{2}^{2}+Z_{m e c h, 2}}=\frac{I_{1} \tau_{1} A_{1}}{A_{1}^{2 T(1,2)-T(2,2) Z_{\text {exp }}}+Z_{\text {mech }, 1}}\left[T(2,1) \frac{T(1,2)-T(2,2) Z_{\text {exp }}}{T(2,1) Z_{\text {exp }}-T(1,1)}+T(2,2)\right]$.

Given $Z_{\text {exp }}$ and $p_{\text {exp }}$, the current in C2 $I_{2}$ is obtainable from Eq. (18). Then, the current in C1 $I_{1}$ is obtainable from Eq. (19), which equation implies that any acoustic field can be satisfied by the two currents.

For experimental analysis, the impedance of the $\mathrm{RC}$ load is found from

$$
Z_{\text {ori }}=\frac{p_{3}}{U_{\text {ori }}}=\frac{\gamma p_{3} P_{a}}{i \omega p_{\text {res }} V_{\text {res }}}
$$

The acoustic impedance at the double-acting piston facing to the orifice is

$$
Z_{3}=1 /\left(\frac{i \omega V_{3}}{\gamma P_{a}}+\frac{1}{Z_{\text {ori }}}\right)=1 /\left(\frac{i \omega V_{3}}{\gamma P_{a}}+\frac{i \omega p_{\text {res }} V_{\text {res }}}{\gamma p_{3} P_{a}}\right)=\frac{\gamma P_{a}}{i \omega\left(V_{3}+p_{\text {res }} V_{\text {res }} / p_{3}\right)},
$$

which then gives the acoustic impedance $Z_{\text {exp }}$ 


$$
Z_{\text {exp }}=\frac{p_{\text {exp }}}{U_{3}}=\frac{p_{\text {exp }} Z_{3}}{p_{3}}=\frac{\gamma p_{\text {exp }} P_{a}}{i \omega\left(p_{3} V_{3}+p_{\text {res }} V_{\text {res }}\right)}
$$

Hence, for experimental analysis, the practical acoustic field can be obtained from $p_{\text {res }}, p_{\text {exp }}$ and $p_{3}$ without any flow field imaging equipment.

\section{PRACTICAL CASE DESIGN}

The regenerative component is a pulse tube cryocooler consisting of a heat rejecter, a regenerator, a cold tip, a pulse tube, and a flow straightener. Table 1 lists the main parameters of this cryocooler and the two compressors [21]. The volume of the reservoir is $5 \mathrm{~L}$. The design pressure amplitude in the expansion chamber $p_{\text {exp }}$ is $0.25 \mathrm{MPa}$. Based on the numerical model in [19], we derive the transmission matrix,

$$
\left[\begin{array}{ll}
T(1,1) & T(1,2) \\
T(2,1) & T(2,2)
\end{array}\right]=\left[\begin{array}{cc}
0.990+0.0952 i & (-58.9-5.59 i) \times 10^{5} \\
(1.35-25.1 i) \times 10^{-9} & 0.252+0.132 i
\end{array}\right] .
$$

If $Z_{\text {exp }}=4.4 \times 10^{7} \angle 60^{\circ} \mathrm{Pa} \cdot \mathrm{m} / \mathrm{s}$ (with this impedance, the relative Carnot efficiency from acoustic to cooling power is about $32 \%$ ) is desired, the acoustic impedance $Z_{1}$ (which equals $\left.Z_{\text {com }}\right)$ is $2.44 \times 10^{7} \angle-25.7^{\circ} \mathrm{Pa} \cdot \mathrm{m} / \mathrm{s}$.

\subsection{Design for Config. 1}

If the real part of $Z_{\text {ori }}$ is set to $4.41 \times 10^{7}$ (This value is not special, but it must ensure that the acoustic power consumed by the orifice is more than that flowing out of the regenerative part. The imaginary part can be calculated from the reservoir volume), then from Eq. (16), $Z_{2}$ is $4.15 \times 10^{7} \angle-62.3^{\circ} \mathrm{Pa} . \mathrm{m} / \mathrm{s}$. The optimum diameter for $\mathrm{C} 2$ is [20]

$$
D_{\text {opt }, 2}=2 \sqrt{\left\{\frac{\left[\operatorname{Re}\left(Z_{\text {mech }, 2}\right)\right]^{2}}{\left[\operatorname{Re}\left(Z_{2}\right)\right]^{2}}\left[\frac{\tau_{2}^{2}}{\operatorname{Re}\left(Z_{\text {elec }, 2}\right) \operatorname{Re}\left(Z_{\text {mech }, 2}\right)}+1\right]\right\}^{1 / 4} / \pi}=0.0881 \mathrm{~m}
$$

and the mass of the piston at resonance is

$$
M_{2}=\frac{-\operatorname{Im}\left(Z_{2}\right) A_{2}^{2}+K_{2} / \omega}{\omega}=4.857 \mathrm{~kg} .
$$


Similarly, for $\mathrm{C} 1$, the optimum diameter $D_{o p t, 1}$ is $0.0853 \mathrm{~m}$ and the mass of the piston at resonance $M_{1}$ is $1.608 \mathrm{~kg}$. With these values for diameter and mass, we obtain the currents in $\mathrm{C} 1$ and $\mathrm{C} 2$ of $21.7 \angle 27.9^{\circ}$ and $9.4 \angle 62.3^{\circ} \mathrm{A}$, respectively.

If $Z_{\text {exp }}$ varies and the parameters of the compressors do not change, the compressors will not resonate. How will the currents vary then? Figures 2 and 3 present the influence of the phase of $Z_{\text {exp }}$ on the currents in the two compressors. The moduli of the currents do no vary much with the phase of $Z_{\text {exp }}$ varying from $80^{\circ}$ to $20^{\circ}$, which aids in the design of the compressors. If the currents increase too much, the diameter of the coil wires need to be especially enlarged. The efficiency of $\mathrm{C} 1$ (Fig. 4) is almost constant; however, the efficiency of $\mathrm{C} 2$ drops a little quickly as the phase of $Z_{\text {exp }}$ decreases. From the output acoustic power of the two compressors (Fig. 5), $W_{\text {output, } 1}$ of $\mathrm{C} 1$ is much bigger than $W_{\text {output, } 2}$ of $\mathrm{C} 2$ when the phase of $Z_{\text {exp }}$ is small. This is one of the reasons for the larger current modulus in $\mathrm{C} 1$ than in $\mathrm{C} 2$. With the phase of $Z_{\text {exp }}$ varying from $30^{\circ}$ to $80^{\circ}$, the phase difference between $U_{c o m}$ and $U_{\text {exp }}$ varies from $67.6^{\circ}$ to $113.6^{\circ}$ (Fig. 6). At the same time, the phase of $I_{1}$ first leads that of $I_{2}$ by about $38^{\circ}$ and then lags by about $69^{\circ}$ (Fig. 3).

If a higher pressure in the expansion chamber is wanted, $\mathrm{C} 1$ needs to output more acoustic power. For example, $W_{\text {output, } 1}$ is $10 \mathrm{~kW}$ if $p_{\text {exp }}$ is $0.4 \mathrm{MPa}$ and the phase of $Z_{\text {exp }}$ is $30^{\circ}$. To satisfy the experiment, the power capacity of $\mathrm{C} 1$ should be sufficiently large. In contrast, it is always possible for $\mathrm{C} 2$ to function at a relative small output power because the resistance of the orifice can be adjusted in the experiment. Figure 7 shows the influence of the phase of $Z_{\text {exp }}$ on the modulus of the current in $\mathrm{C} 2$ with different output power of $\mathrm{C} 2$. For each curve in this figure, the orifice resistance is adjusted to maintain a constant output power 
in C2. Comparing the curves, the modulus of the current is smaller with less output power. This is helpful in preventing the current in $\mathrm{C} 2$ from exceeding specifications.

Figure 8 shows the influence of pressure in the expansion chamber and output acoustic power on the current in $\mathrm{C} 2$. In this calculation, the phase of $Z_{\text {exp }}$ is set at $30^{\circ}$, which implies that $\mathrm{C} 2$ does not acoustically match $Z_{\text {exp }}$. When the pressure in the expansion chamber is relatively high, the modulus of the current in C2 varies slightly even though the output power is very small. Hence, the current capacity of $\mathrm{C} 2$ need to be adequately sufficient if the pressure is to vary over a wide range.

\subsection{Design for Config. 2}

Here, there is $Z_{2}=Z_{\text {exp }}$. If the real part of $Z_{3}$ be $4.37 \times 10^{7}$ (For simplicity, $V_{3}$, the volume between the right piston surface of $\mathrm{C} 2$ and the orifice is set as zero, so $Z_{3}$ equals to $Z_{\text {ori }}$. The value for $Z_{3}$ is not special, but it must ensure that the acoustic power consumed by the orifice is more than that flowing out of the regenerative part), the optimum diameter for C2 is $D_{o p t, 2}=0.0855 \mathrm{~m}$, and the mass of the piston at resonance is $M_{2}=4.839 \mathrm{~kg}$ [10]. The optimum diameter $D_{o p t, 1}$ and the piston mass on resonance $M_{1}$ are the same as those in Section 3.1. With the diameter and mass, we obtain currents in $\mathrm{C} 1$ and $\mathrm{C} 2$ of $21.7 \angle 27.9^{\circ}$ and $9.34 \angle-60^{\circ} \mathrm{A}$.

Figures 9 and 10 show the influence of the phase of $Z_{\text {exp }}$ on the currents in the two compressors. Figure 9 is very similar to Fig. 2, whereas Fig. 10 is quite different to Fig. 3. Figure 11 shows the dependence of current on the phase of $Z_{\text {exp }}$ and the pressure in the expansion chamber when there is no output acoustic power from $\mathrm{C} 2$. When the phase of $Z_{\text {exp }}$ 
is $60^{\circ}$, the piston of $\mathrm{C} 2$ is in a resonant state. The electromagnetic force produced by the current is used to overcome the mechanical resistance. When the phase of $Z_{\text {exp }}$ deviates from $60^{\circ}$, an additional electromagnetic force is needed to change the phase of the piston, so the current is larger.

\section{DISCUSSION}

Assuming that $\mathrm{C} 2$ in Config. 1 is just a mass-spring resonator coupled to the expansion chamber, then there is no coil or magnet. Equation (11) can be written as

$$
Z_{\text {ori }}=\frac{Z_{\text {mech }, 2} Z_{\text {exp }}}{Z_{\text {mech }, 2}-Z_{\text {exp }} A_{2}^{2}}
$$

If $Z_{\text {exp }}=4.4 \times 10^{7} \angle 60^{\circ} \mathrm{Pa} \cdot \mathrm{m} / \mathrm{s}$ and $Z_{\text {mech }, 2}=30+3100 i \mathrm{~N} . \mathrm{m} / \mathrm{s}$, then $Z_{\text {ori }}=8.95 \times$ $10^{7}-1.72 i \times 10^{6} \mathrm{~Pa} . \mathrm{m} / \mathrm{s}$. The corresponding reservoir volume is $9.28 \mathrm{~L}$. Apparently, $Z_{\text {exp }}$ can be achieved by adjusting the orifice and the reservoir volume, which further simplifies the modulation of the acoustic field. Figures 12 and 13 show the corresponding real part of $Z_{\text {ori }}$ and reservoir volume when the phase of $Z_{\text {exp }}$ varies from $30^{\circ}$ to $80^{\circ}$. When $\operatorname{Arg}\left(Z_{\text {exp }}\right)$ varies from $30^{\circ}$ to $40^{\circ}$, the reservoir volume changes slightly, and therefore requires very precise adjustments in reservoir volume. When $\operatorname{Arg}\left(Z_{\text {exp }}\right)$ is near $60^{\circ}$, the volume increases rapidly as in this instance the denominator of Eq. (23) is close to zero. When $\operatorname{Arg}\left(Z_{\text {exp }}\right)$ is larger than $60^{\circ}$, the reservoir volume is negative. Hence, in practice, the phase of $Z_{\text {exp }}$ can only vary within a very limited range if $Z_{m e c h, 2}$ is not changed.

For Config. 2, Eq. (18) can be written

$$
Z_{3}=Z_{\text {exp }}-Z_{\text {mech }, 2} / A_{2}^{2}
$$


In practice, the phase of $Z_{\text {exp }}$ can similarly vary only over a very limited range if $Z_{m e c h, 2}$ is not changed.

\section{CONCLUSIONS}

With two compressors connected to the two ends of a regenerator and a RC load added to dissipate the acoustic work, an alternative method was demonstrated to modulate the acoustic field in regenerators. With this method, the acoustic field varies over a wide range by changing only the current in the two compressors. The impedance $Z_{\text {exp }}$ can easily be obtained using three pressure sensors instead of flow field imaging equipment, thereby greatly simplifying the experiment.

The compressor connected with the expansion chamber can be further simplified using a mass-spring resonator involving no electromagnetic force. By adjusting the orifice and the reservoir volume, the acoustic field varies over a very limited range. For a wider range, other parameters such as mechanical impedance must also be adjusted. But the combination of the mass-spring resonator and the RC load could act as a new phase shifter in pulse tube cryocoolers.

\section{ACKNOWLEDGEMENTS}

This work was supported by the National Sciences Foundation of China (Grant No. 51276187 and 51576204).

\section{REFERENCE}


[1] Radebaugh R, Lewis M, Luo EC. Inertance tube optimization for pulse tube refrigerators. Adv Cryog Eng. 2006; 51 (A): 59-70.

[2] Gifford WE, Longsworth RC. Pulse tube refrigerator. J Eng Ind, Trans ASME. 1964; 86: 264-270.

[3] Mikulin EI. Low-temperature expansion pulse tube. Adv Cryog Eng. 1984; 29: 629-637.

[4] Radebaugh R, Zimmerman J, Smith DR, et al. A comparison of three types of pulse tube refrigerators: new methods for reaching 60K. Adv Cryog Eng. 1986; 31: 779-789.

[5] Zhu SL, Wu PY, Chen ZQ. Double inlet pulse tube refrigerators: an important improvement. Cryogenics. 1990; 30 (6): 514-520.

[6] Godshalk KM, Jin C, Kwong YK, et al. Characterization of $350 \mathrm{~Hz}$ thermoacoustic driven orifice pulse tube refrigerator with measurements of the phase of the mass flow and pressure. Adv Cryog Eng. 1996: 1411-1418.

[7] Wheatley J, Hofler T, Swift GW, et al. An intrinsically irreversible thermoacoustic heat engine. J Acoust Soc Am. 1983; 74 (1): 153-170.

[8] Backhaus S, Swift GW. A thermoacoustic Stirling heat engine. Nature. 1999; 399 (6734): $335-338$.

[9] Berchowitz DM; Lubricant free, reduced mass, free-piston, Stirling machine having reciprocating piston drivingly linked to rotary electromagnetic transducer moving in rotational oscillation. US patent, Patent No. US8713934B2. 2010.

[10]Hu JY, Luo EC, Zhang LM, et al. A double-acting thermoacoustic cryocooler for high temperature superconducting electric power grids. Appl Energ. 2013; 112: 1166-1170.

[11] Antao DS, Farouk B. Numerical and experimental characterization of the inertance effect 
on pulse tube refrigerator performance. International Journal of Heat and Mass Transfer. 2014; 76: 33-44.

[12] Shiraishi M, Murakami M. Visualization of oscillating flow in a double-inlet pulse tube refrigerator with a diaphragm inserted in a bypass-tube. Cryogenics. 2012; 52 (7-9): $410-415$.

[13] Wu ZH, Chen YY, Dai W, et al. Investigation on the thermoacoustic conversion characteristic of regenerator. Appl Energ. 2015; 152: 156-161.

[14]Zhou LH, Xie XJ, Li Q. Study of acoustic field modulation in the regenerator by double loudspeakers method. J Acoust Soc Am. 2011; 130 (5): 2709-2719.

[15]Paek I, Mongeau L, Braun JE, et al. Phase of acoustic impedance and performance of standing wave thermoacoustic coolers. J Mech Sci Technol. 2009; 23 (5): 1476-1484.

[16]Poignand G, Lihoreau B, Lotton P, et al. Optimal acoustic fields in compact thermoacoustic refrigerators. Appl Acoust. 2007; 68 (6): 642-659.

[17]Biwa T, Tashiro Y, Mizutani U, et al. Experimental demonstration of thermoacoustic energy conversion in a resonator. Phys Rev E. 2004; 69 (6): 066304.

[18] Kato Y, Baba K. Empirical estimation of regenerator efficiency for a low temperature differential Stirling engine. Renew Energ. 2014; 62: 285-292.

[19] Hu JY, Dai W, Luo EC, et al. Development of high efficiency Stirling-type pulse tube cryocoolers. Cryogenics. 2010; 50 (9): 603-607.

[20] Swift GW. Thermoacoustics: A unifying perspective for some engines and refrigerators. Sewickley PA: ASA Publication, 2002.

[21]Zhang LM, Hu JY, Wu ZH, et al. A 1 kW-class multi-stage heat-driven thermoacoustic 
cryocooler system operating at liquefied natural gas temperature range. Appl Phys Lett. 2015; 107 (3): 033905. 


\section{FIGURE CAPTIONS}

Figure 1 Two configurations for acoustic field modulation.

Figure 2 Influence of the phase of $Z_{\text {exp }}$ on the modulus of the currents in the two compressors.

Figure 3 Influence of the phase of $Z_{\text {exp }}$ on the phase of the currents in the two compressors.

Figure 4 Influence of the phase of $Z_{\text {exp }}$ on the efficiency of the two compressors.

Figure 5 Influence of the phase of $Z_{\exp }$ on the output acoustic power of the two compressors.

Figure 6 Influence of the phase of $Z_{\text {exp }}$ on the phase difference between $U_{\text {com }}$ and $U_{\text {exp. }}$

Figure 7 Influence of the phase of $Z_{\text {exp }}$ on the modulus of the current in $\mathrm{C} 2$ with constant output power of $\mathrm{C} 2$.

Figure 8 Influence of pressure in the expansion chamber and the output acoustic power on the current in $\mathrm{C} 2$.

Figure 9 Influence of phase of $Z_{\text {exp }}$ on the modulus of currents in the two compressors.

Fig.10 Influence of phase of $Z_{\text {exp }}$ on the modulus of the current in $\mathrm{C} 2$ at constant output power of $\mathrm{C} 2$.

Figure 11 Influence of $\operatorname{Arg}\left(Z_{\text {exp }}\right)$ and $p_{\text {exp }}$ on the modulus of the currents in C2.

Figure $12 \operatorname{Influence}$ of $\operatorname{Arg}\left(Z_{\text {exp }}\right)$ and $\operatorname{Im}\left(Z_{\text {mech, } 2}\right)$ on the real part of $Z_{\text {ori }}$.

Figure 13 Influence of $\operatorname{Arg}\left(Z_{\text {exp }}\right)$ and $\operatorname{Im}\left(Z_{m e c h, 2}\right)$ on the reservoir volume. 
TABLE 1 Main parameters of the pulse tube cryocooler and two compressors

\begin{tabular}{ll}
\hline Parameters & Value \\
\hline Working frequency & $50 \mathrm{~Hz}$ \\
Working gas & Helium \\
Charging pressure & $3 \mathrm{MPa}$ \\
Cooling temperature & $80 \mathrm{~K}$ \\
Heat rejecter & $\emptyset 75 \mathrm{~mm} \times \mathrm{L} 64 \mathrm{~mm}$ \\
Diameter and length of regenerator & $\varnothing 75 \mathrm{~mm} \times \mathrm{L} 70 \mathrm{~mm}$ \\
Cold tip & $\emptyset 75 \mathrm{~mm} \times \mathrm{L} 30 \mathrm{~mm}$ \\
Diameter and length of pulse tube & $\emptyset 37 \mathrm{~mm} \times \mathrm{L} 150 \mathrm{~mm}$ \\
Flow straightener & $\varnothing 37 \mathrm{~mm} \times \mathrm{L} 5 \mathrm{~mm}$ \\
transduction coefficient & $80 \mathrm{~N} / \mathrm{A}$ \\
Mechanical resistance & $50 \mathrm{~N} . \mathrm{m} / \mathrm{s}$ \\
Electrical resistance & $0.5 \Omega$ \\
Spring constant & $5 \times 10^{4} \mathrm{~N} / \mathrm{m}$ \\
\hline
\end{tabular}




\section{Figure1}
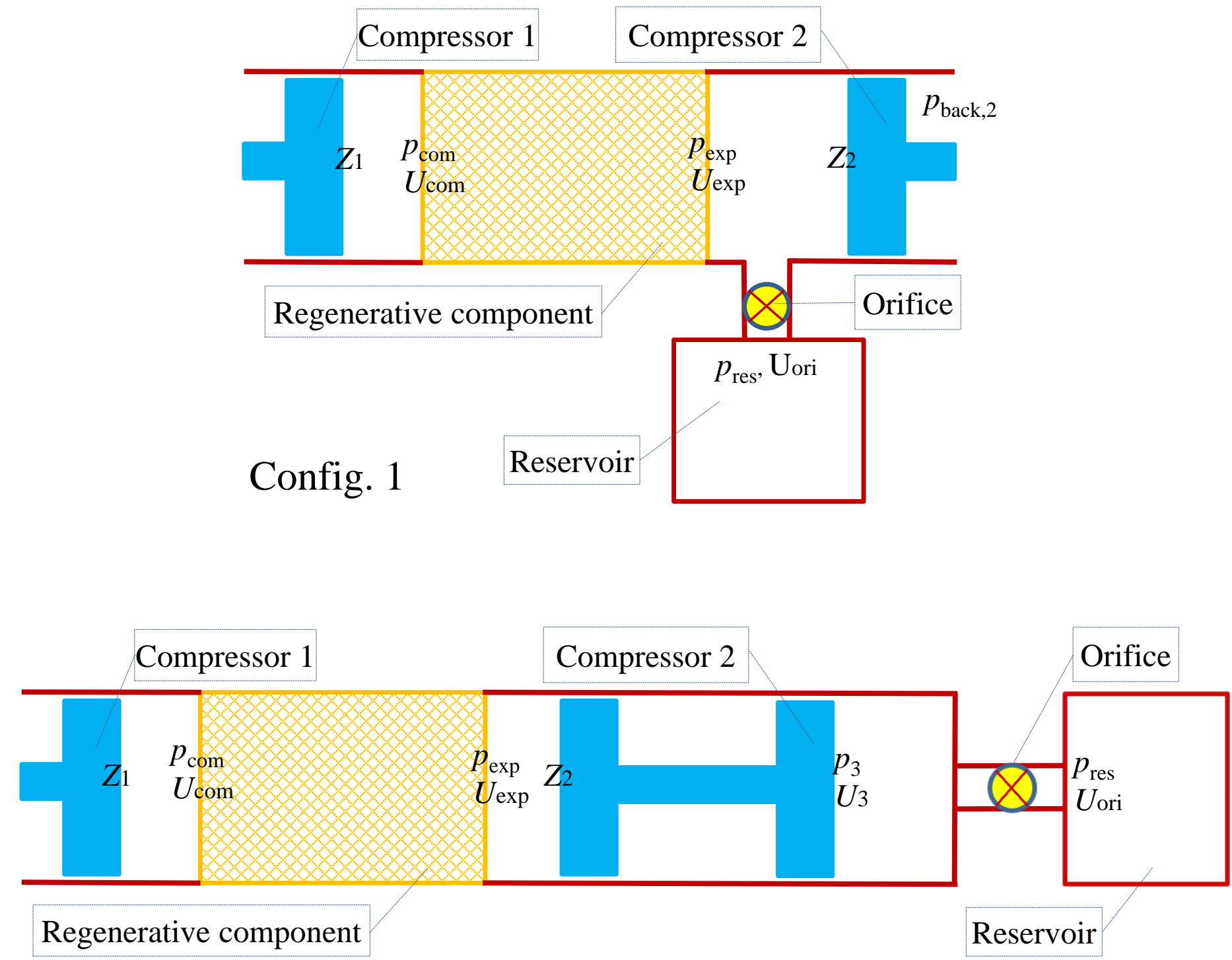

Config. 2 
Figure2

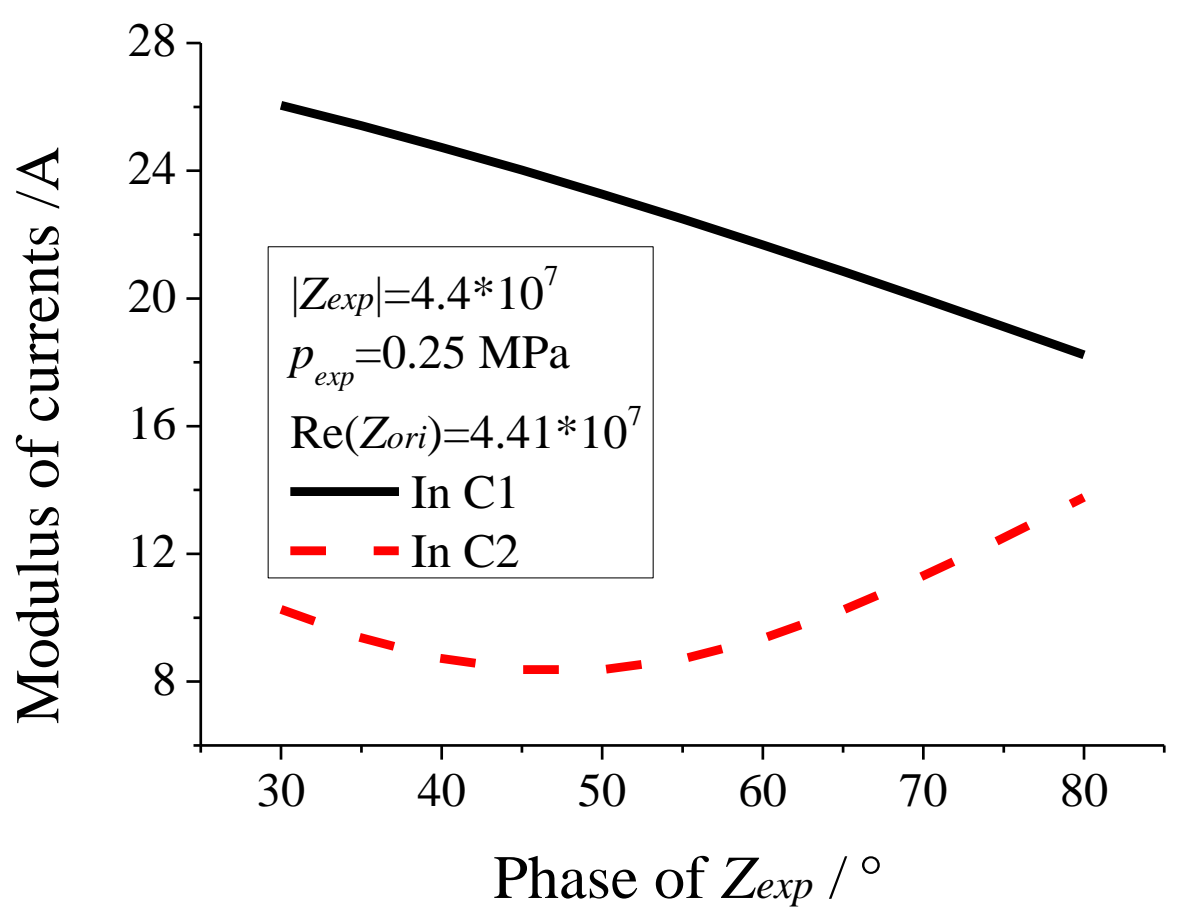


Figure 3

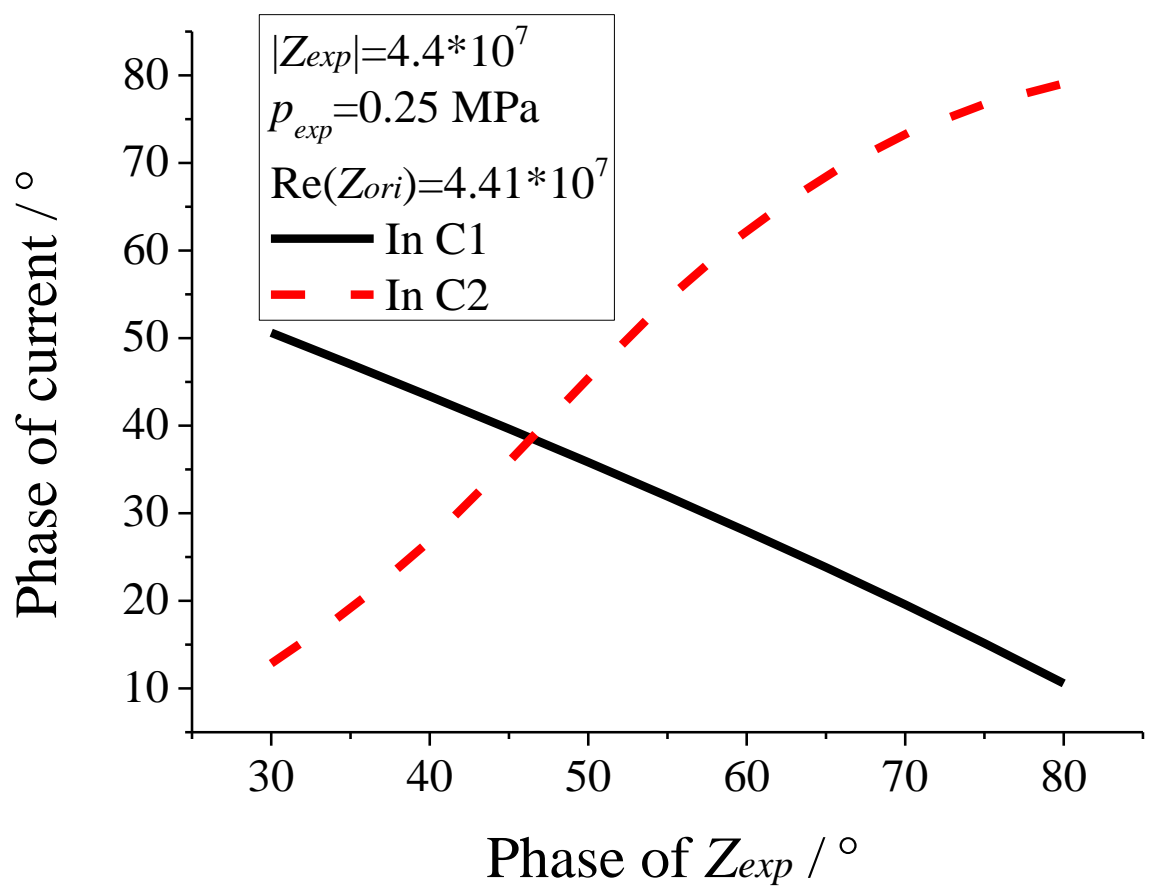


Figure 4

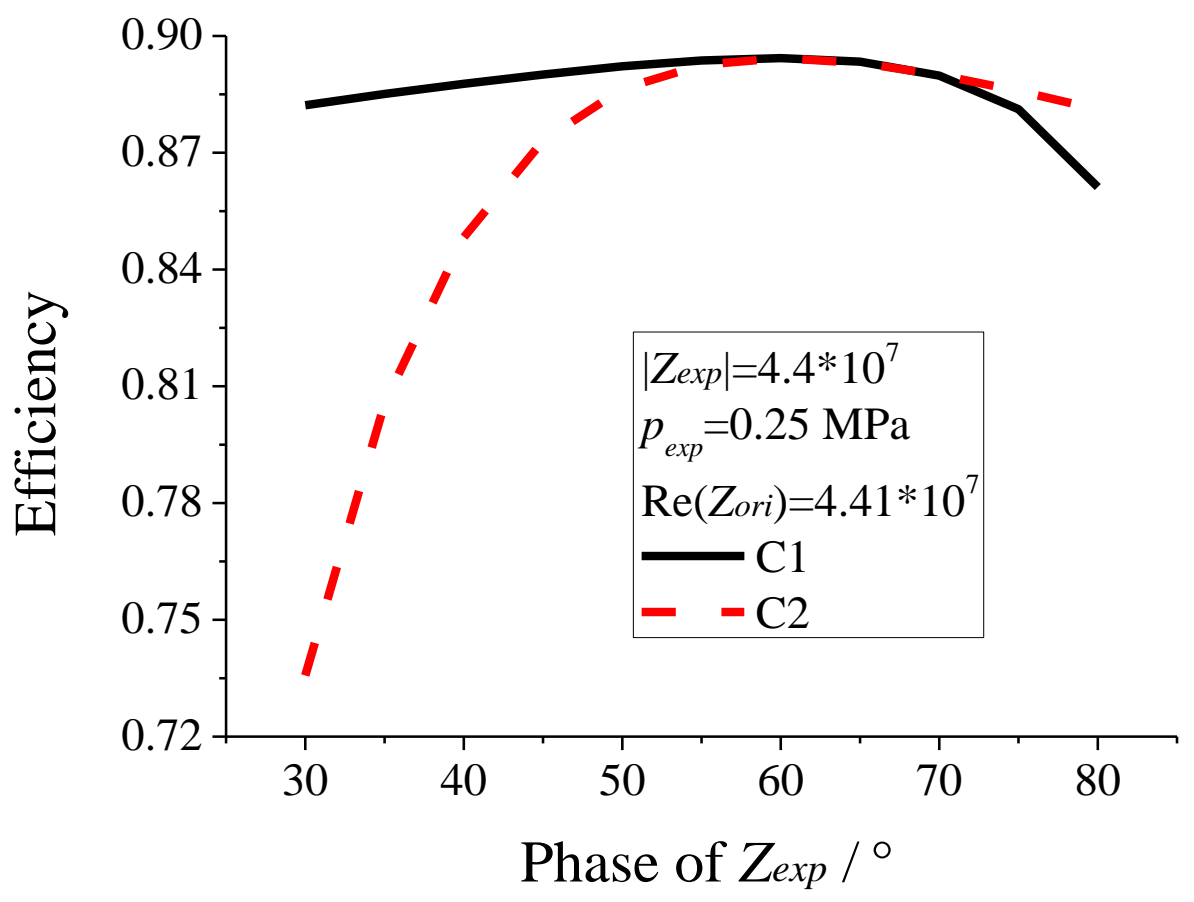


Figure5

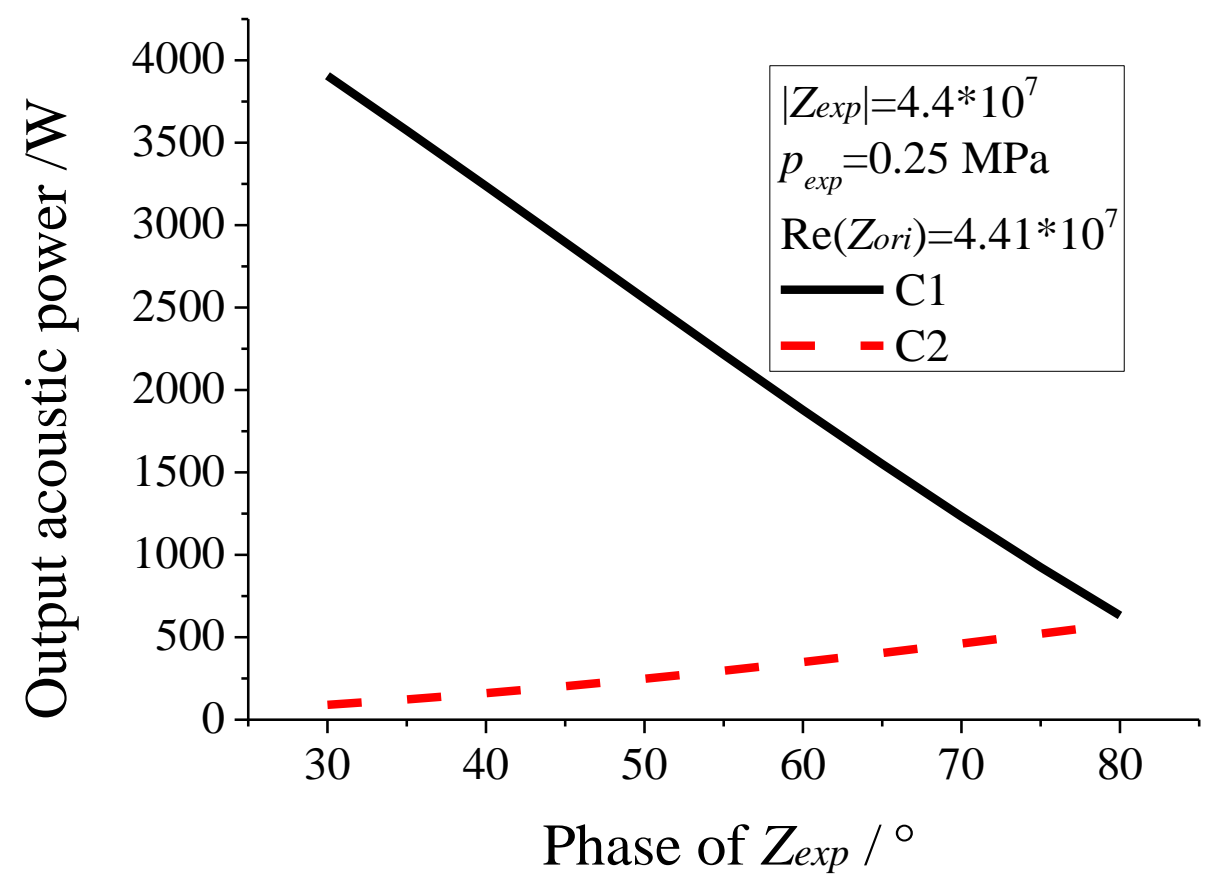


Figure 6

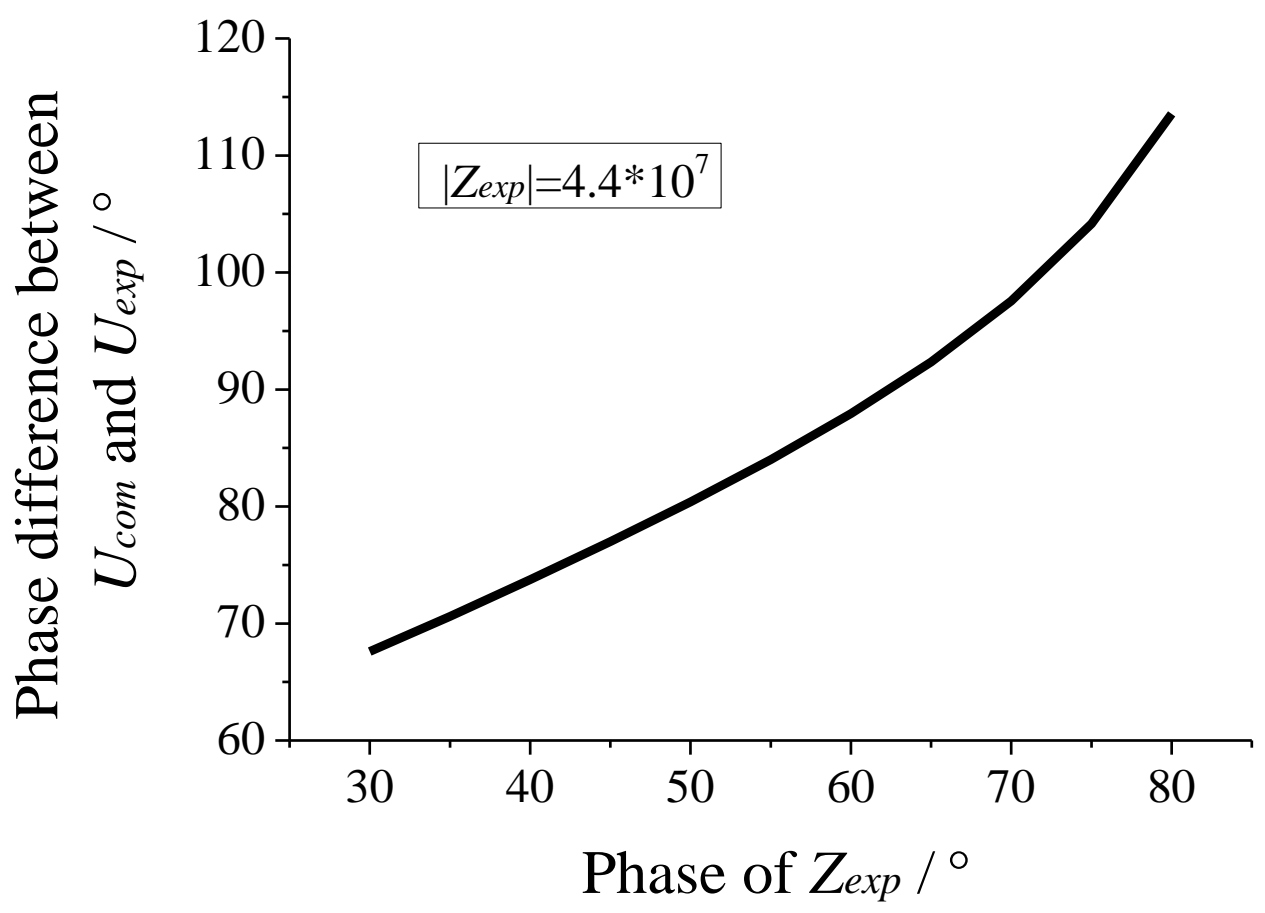


Figure 7

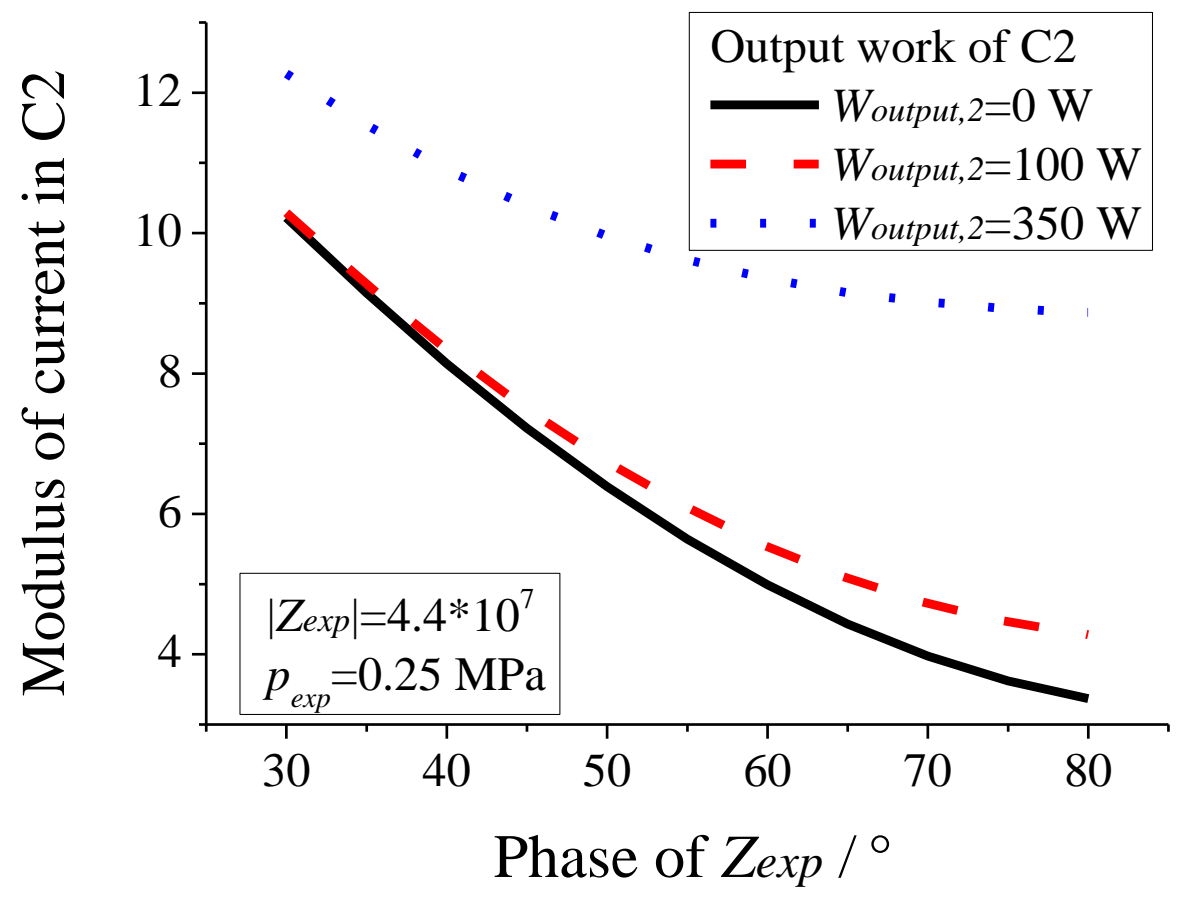


Figure 8

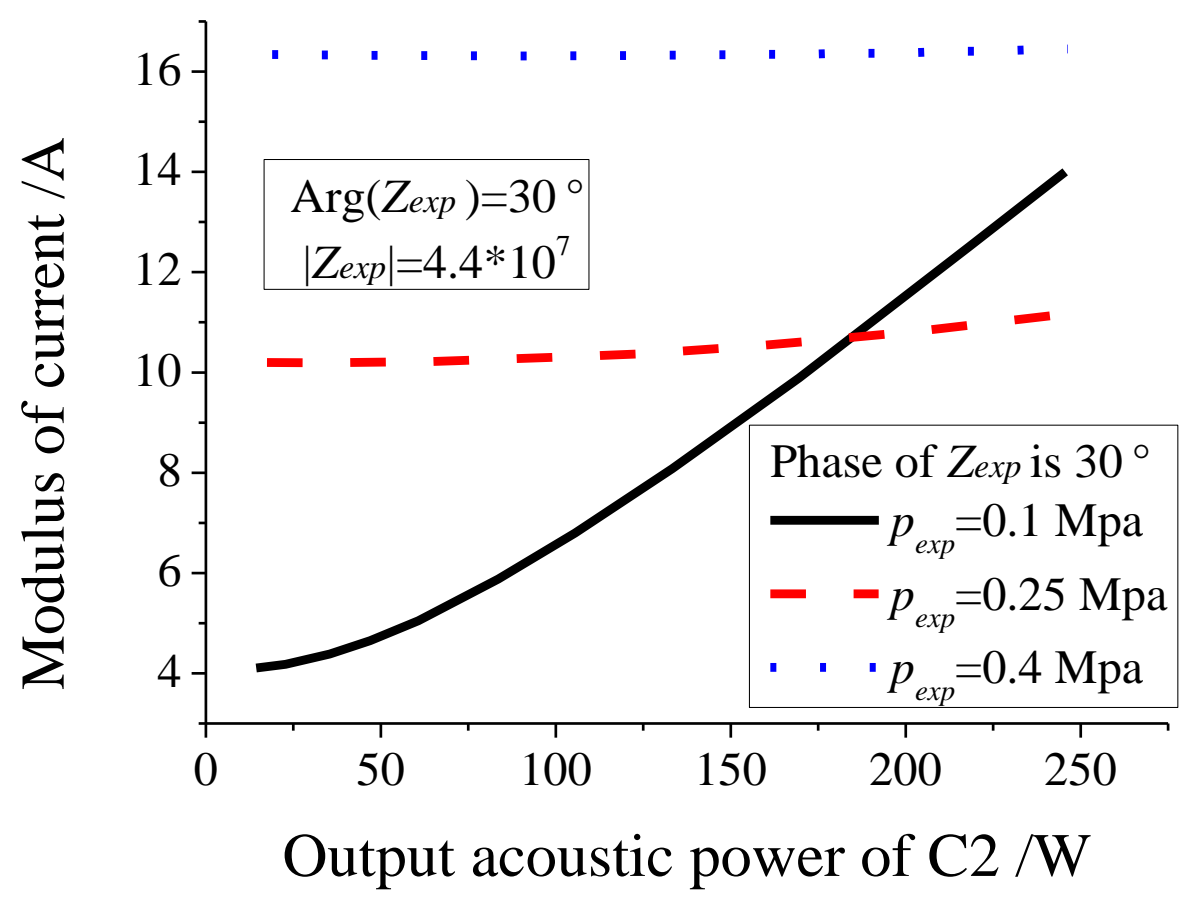


Figure 9

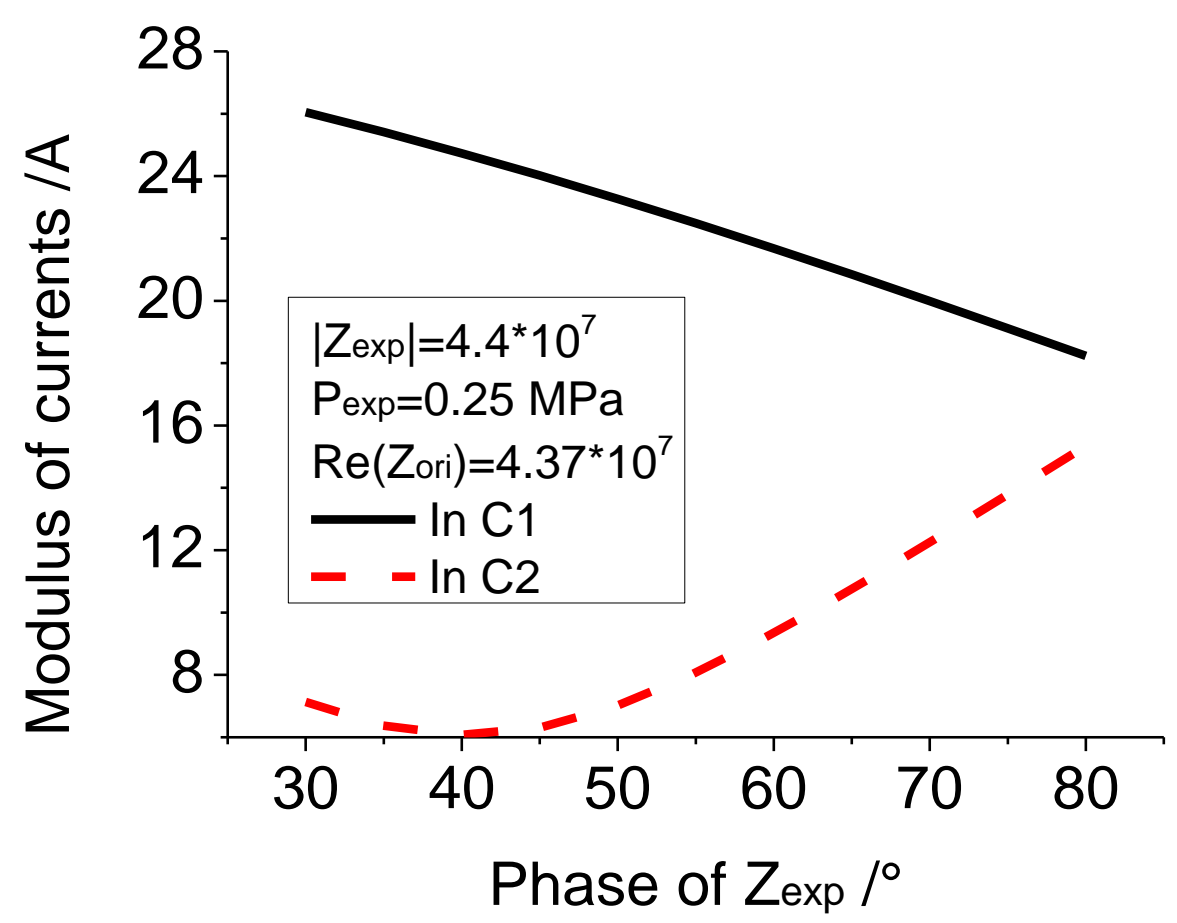


Figure 10

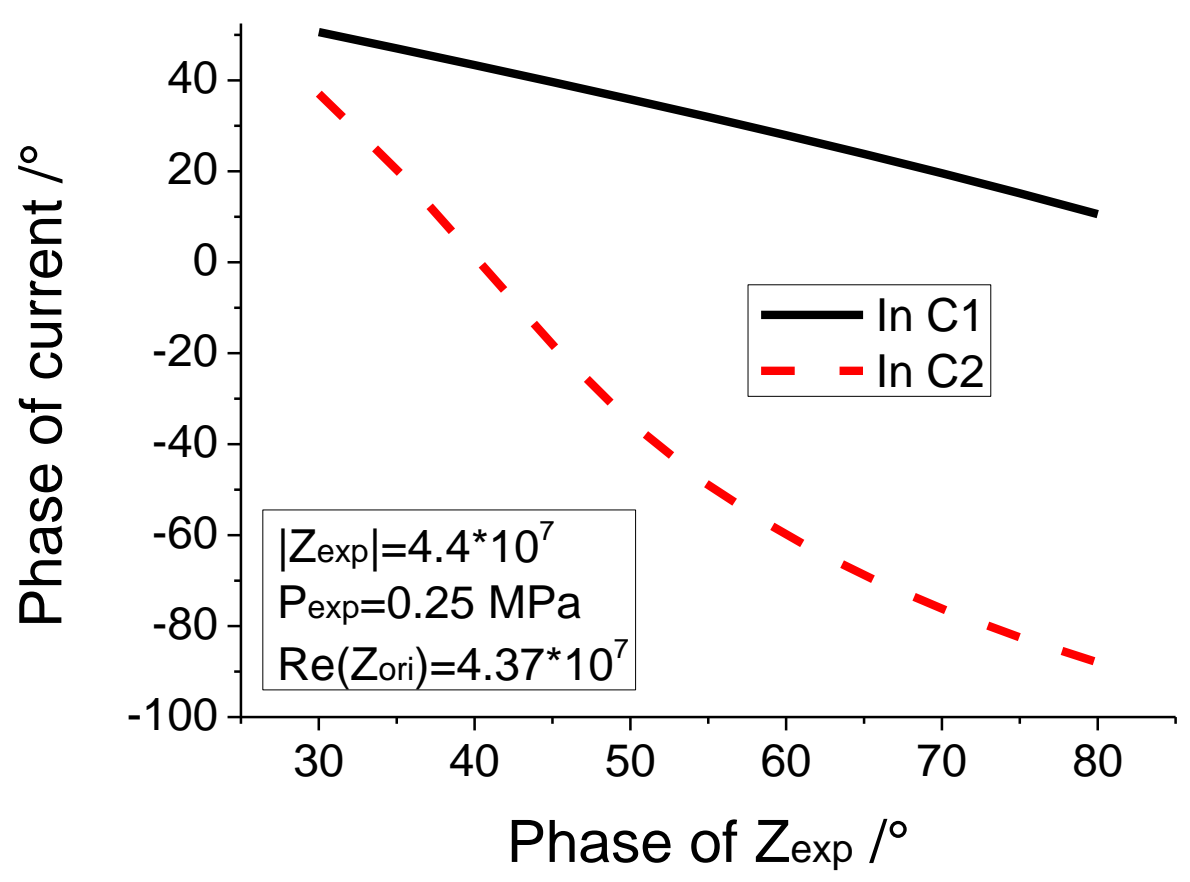


Figure 11

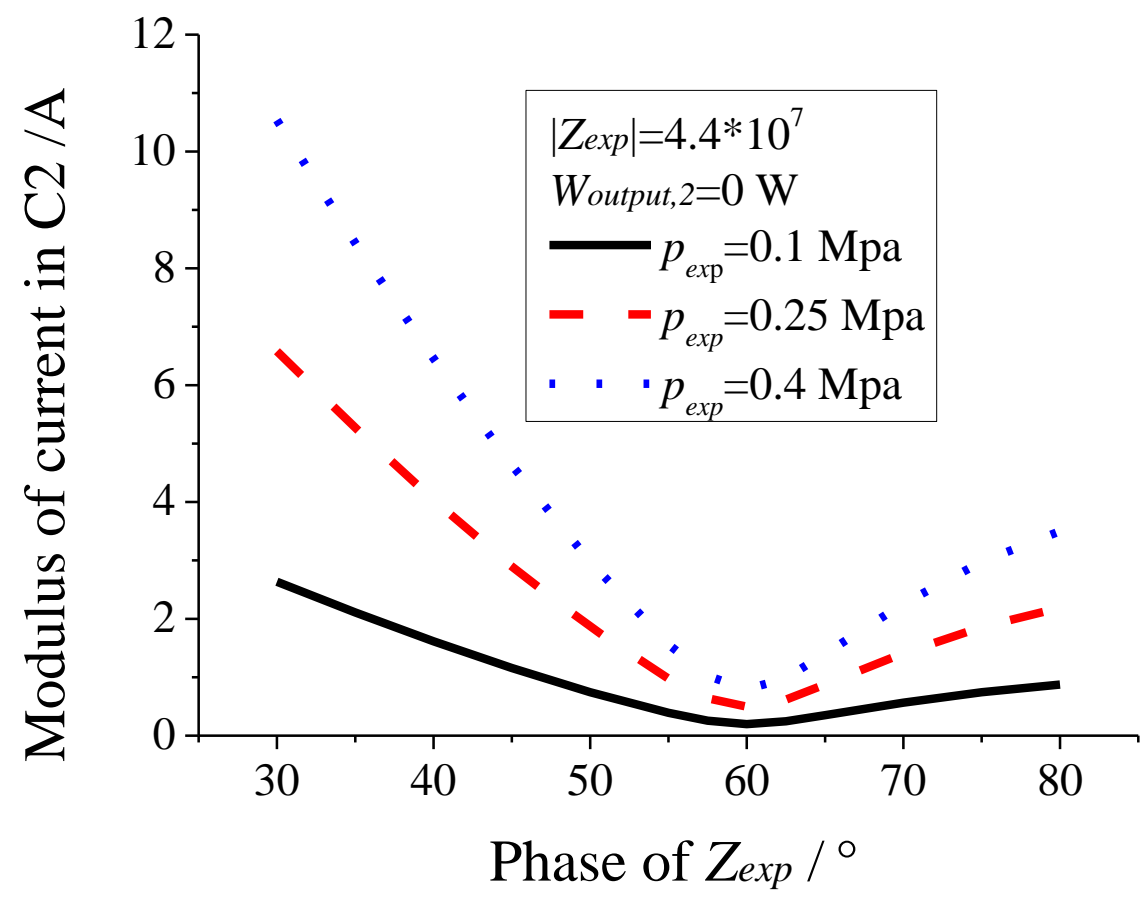


Figure 12

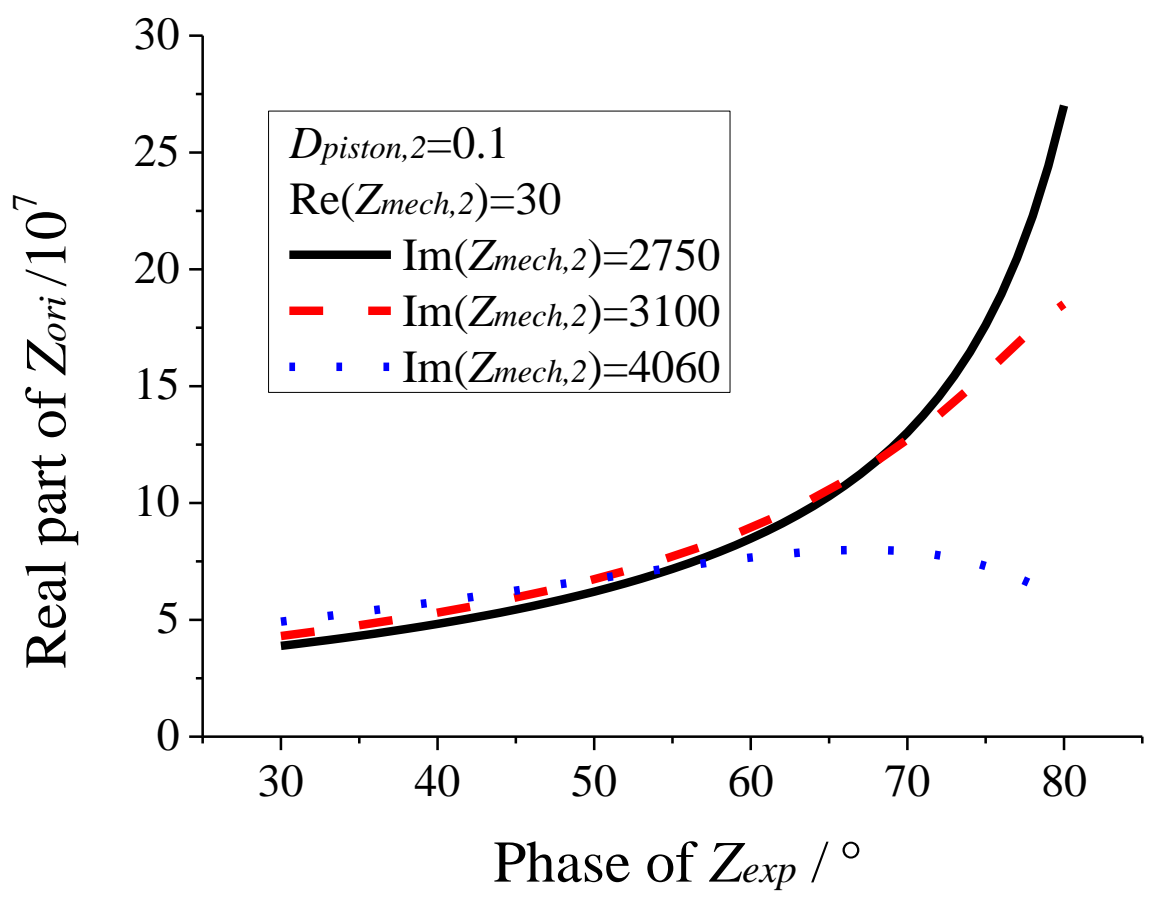


Figure 13

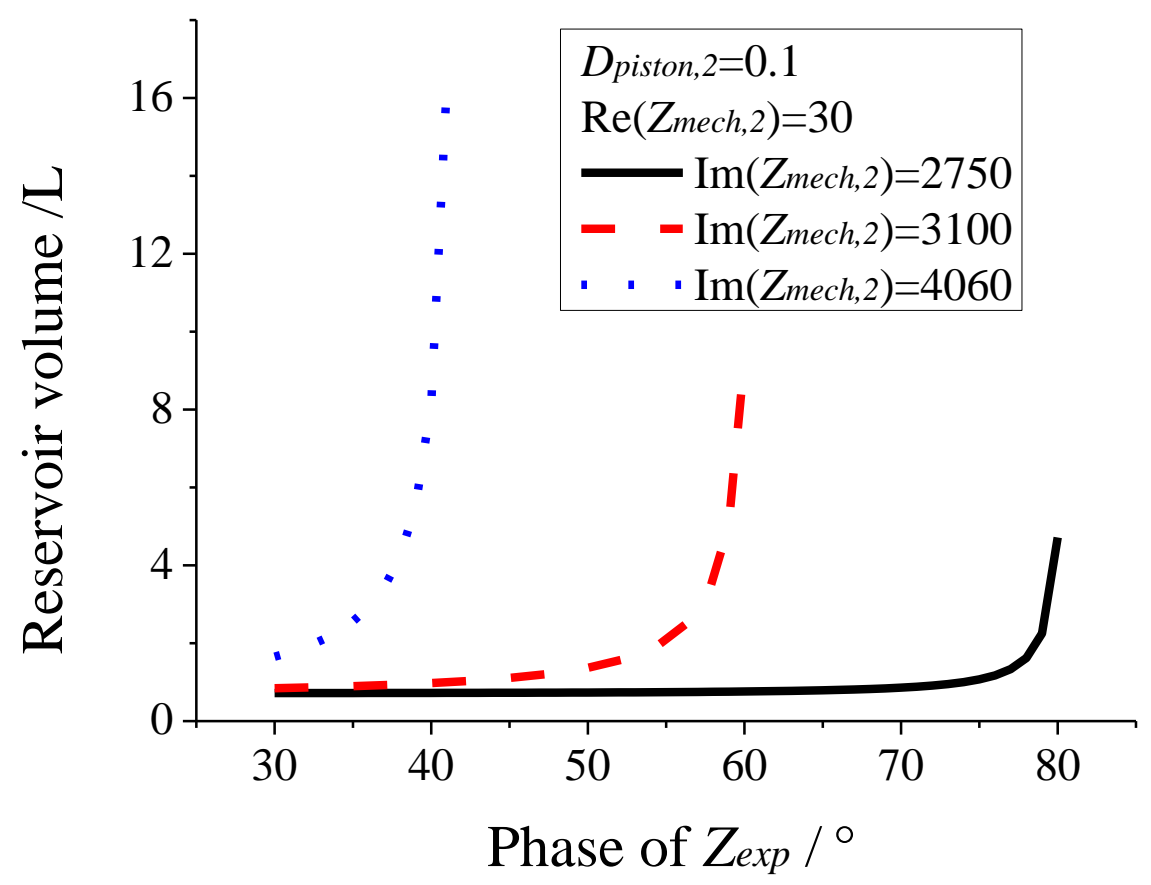

